DOI:

\title{
Gökçeada Sıcaklık ve Deniz Suyu Sıcaklıklarının Eğilim Analizi
}

\author{
Fevziye Ayça SARAÇOĞLU ${ }^{*}$ \\ ${ }^{1}$ Yıldız Teknik Üniversitesi, İnşaat Mühendisliği Bölümü, İstanbul, Türkiye. \\ ORCID: 0000-0002-9626-7652
}

Geliş Tarihi: 25.09 .2019

*Sorumlu Yazar e mail: favarol@inm.yildiz.edu.tr Kabul Tarihi: 04.10 .2019

Atıf/Citation: Saraçoğlu, F.A. "Gökçeada Sıcaklık ve Deniz Suyu Sıcaklıklarının Eğilim Analizi”, Haliç Üniversitesi Fen Bilimleri Dergisi 2020, 3/1: 1-17.

Araştırma Makalesi/ Research Article

\section{Özet}

Sıcaklık ve deniz suyu sıcaklıkları (DSS) günümüzde en çok atmosferik değişimin belirlenmesinde, modellenmesinde ve gelecek dönemlerin tahmininde kullanılmakla birlikte; balıkçılık, denizcilik, iklim değişikliği, oşinografi açılarından da önemli parametrelerdir.

Bu çalışmada Ege Denizi'nin kuzeyinde yer alan Türkiye'nin en büyük adası olan Gökçeada için sıcaklık ve DSS'nin zamanla değişimi ve eğilimi araştırılmıştır. 20062015 arasındaki zaman dilimi için Meteoroloji Genel Müdürlüğünden alınan ölçüm verileri aylık ortalama, aylık minimum ve aylık maksimum DSS olarak elde edilmiş; aylık, mevsimsel ve yıllık olarak incelenmiştir. Ayrıca yıllık ortalama, yıllık minimum ve yıllık maksimum değerlerinin analizi ile ekstrem durumlar belirlenmiştir. Eğilim analizi için en küçük kareler yöntemi ve Theil-Sen metodu, veri setlerinin istatistiksel olarak belirginliğini belirlemek için de Mann Kendall metodu kullanılmıştır.

10 yıllık veri setlerinin bütün hesaplanan serilerinin homojenliği 4 farklı metot ile irdelenmiş, tümünün homojen olduğu belirlenmiştir. Yıllık ortalama analizlerde, aylık oluşan ekstrem durumların etkisinin azaldığ1 görülmüştür. Hesaplanan bütün maksimum değerlerin azalan eğilim, bütün minimum değerlerin de artan eğilim gösterdiği belirlenmiştir. Aylık ortalama DSS, yaz mevsiminde azalan eğilim ve kış mevsimi için artan eğilim belirlenmiştir. Aylık minimum DSS sadece kış mevsiminde artış eğilimi sergilerken, diğer mevsimlerde azalma eğilimi göstermiştir. Aylık maksimum DSS ise çoğunlukla ilkbahar ve yaz mevsimlerinde azalan eğilim sergilerken, sonbahar ve kış mevsimlerinde artış eğilimi göstermiştir.

Anahtar Kelimeler: Sıcaklık, Deniz suyu sıcaklığı, İklim Değişikliğii, Eğilim Analizi. 


\title{
The Trend Analysis of Temperature and Sea Surface Temperature in Gökçeada
}

\begin{abstract}
Temperature and Sea Surface Temperature (SST), nowadays, besides having been mostly used in detecting the atmospheric changes, its modeling and prediction for future periods, these parameters are also important for fishery, marine, climate change, and oceanography.

In this study, for Gökçeada, located in the North of The Aegean Sea and having been the largest island of Turkey, temperature and the variations in time and trends of SST have been investigated. For the period between 2005-2016, monthly mean, monthly minimum and monthly maximum temperatures and SST are analyzed monthly, seasonally and annually from the data obtained from the Turkish State Meteorological Service. Also, by means of analyzing annual mean, annual minimum and annual maximumvalues extreme conditions are determined. Least square and Theil Sen Methods for trend analysis, Mann Kendall Test to determine the statistical precision of trends have been used.

The all 10-year data sets with all their calculated series being homogen with 4 different methods is determined. The decrease in monthly extreme conditions in annual mean analysis is detected. It is determined that all the calculated maximum data has shown the decreasing trend while all the minimum data has shown the increasing trend.The monthly mean of SST has been determined as the decreasing trend for summer season and the increasing trend for winter season. The monthly minimum SST has displayed increasing trend only for winter season while showing decreasing trend for other seasons. The monthly maximum SST on the other hand has displayed decreasing trend mostly for spring and summer seasons while showing increasing trend for autumn and winter seasons.
\end{abstract}

Keywords: Temperature, Sea Surface Temperature, Climate Change, Trend Analysis.

\section{Giriş}

Deniz suyu sıcaklıkları (DSS) günümüzde en çok atmosferik değişimin belirlenmesinde, modellenmesinde ve gelecek dönemlerin tahmininde kullanılmakla birlikte; balıkçılık, denizcilik, iklim değişikliği, oşinografi açılarından da önemli parametrelerden biridir. Genel 
hidrolojik çevrim ve fırtına gibi birçok meteorolojik değişiklik ile ilgili olan bu parametre; denizler, okyanuslar ve atmosfer arasındaki ilişkinin belirlenmesinde kullanılmaktadır. Deniz suyu sıcaklıklarının (DSS) değişimi iklim değişikliği ile doğrudan ilişkilidir.

[1]'de DSS ölçümlerinin 20.yy'ın başından itibaren artış gösterdiği belirtilmiş, 19.yy’ın sonlarından itibaren dünyanın birleştirilmiş kara ve deniz yüzey sicaklıklarının da lineer olarak arttığı ve 18802012 yılları arasında ortalama $0.85{ }^{\circ} \mathrm{C}$ civarında artış olduğu belirtilmiştir. Tablo 1'de [1]'de verilmiş olan, 2012'ye kadar farklı zaman aralıkları ve farklı veri setleri için küresel ortalama DSS'nin \%90 güven aralığında elde edilmiş artış değerleri $\left({ }^{\circ} \mathrm{C} / 10 \mathrm{y} 1\right)$ verilmiştir. $\mathrm{Bu}$ rapora göre, farklı veri setleri için; daha kısa zaman periyodunda (1979-2012) yani incelenen son 34 yılda diğer incelenen zaman aralıklarına göre artışın daha büyük olduğu görülmektedir.

Tablo 1. Küresel Ölçekte DSS'nin Farklı Veri Setleri için Artış Değerleri $\left({ }^{\circ} \mathrm{C} / 10\right.$ y1l) [1]

$1880-2012 \quad 1901-2012 \quad 1901-1950 \quad 1951-2012 \quad 1979-2012$

\begin{tabular}{cccccc}
\hline $\begin{array}{c}\text { HadISST } \\
{[2]}\end{array}$ & $\mathbf{0 . 0 4 2}$ & $\mathbf{0 . 0 5 2}$ & $\mathbf{0 . 0 6 7}$ & $\mathbf{0 . 0 6 4}$ & $\mathbf{0 . 0 7 2}$ \\
$( \pm 0.007)$ & $( \pm 0.007)$ & $( \pm 0.024)$ & $( \pm 0.015)$ & $( \pm 0.024)$ \\
\hline $\begin{array}{c}\text { COBE-SST } \\
{[3]}\end{array}$ & - & $\mathbf{0 . 0 5 8}$ & $\mathbf{0 . 0 6 6}$ & $\mathbf{0 . 0 7 1}$ & $\mathbf{0 . 0 7 3}$ \\
$( \pm 0.007)$ & $( \pm 0.032)$ & $( \pm 0.014)$ & $( \pm 0.020)$ \\
\hline $\begin{array}{c}\text { ERSSTv3b } \\
{[4]}\end{array}$ & $\mathbf{0 . 0 5 4}$ & $\mathbf{0 . 0 7 1}$ & $\mathbf{0 . 0 9 7}$ & $\mathbf{0 . 0 8 8}$ & $\mathbf{0 . 1 0 5}$ \\
& $( \pm 0.015)$ & $( \pm 0.011)$ & $( \pm 0.05)$ & $( \pm 0.017)$ & $( \pm 0.031)$ \\
\hline $\begin{array}{c}\text { HadSST3 } \\
{[5]}\end{array}$ & $\mathbf{0 . 0 5 4}$ & $\mathbf{0 . 0 6 7}$ & $\mathbf{0 . 1 1 7}$ & $\mathbf{0 . 0 7 4}$ & $\mathbf{0 . 1 2 4}$ \\
& $( \pm 0.012)$ & $( \pm 0.013)$ & $( \pm 0.028)$ & $( \pm 0.027)$ & $( \pm 0.030)$ \\
\hline
\end{tabular}

Akdeniz ve Ege Denizi DSS'nin eğilim analizi birçok araştırmacı tarafından gerçekleştirilmiş ve birçoğunda tüm bölge ve alt bölgeler için artış eğilimi belirlenmiştir.

[6]'da tüm Akdeniz için uydu verilerini kullanarak yaptıkları çalışmalarında 1985-1996 tarihleri arasında belirgin bir eğilim tespit edememişlerdir. [7]'de 1992-2005 yılları arası için uydu verileri ile yaptıkları 
çalışmalarında Akdeniz için DSS'de $0.06{ }^{\circ} \mathrm{C} / \mathrm{y} 1 \mathrm{l}$ artış belirlemiştir. [8] 'de Kuzey Ege için yaptığı çalışmasında, MEDAR projesi kapsamında ölçülmüş veriler ile 1960-2000 yılları arasındaki deniz suyu sıcaklık ve tuzluluk değişimini incelemiştir. Araştırmacı 10 yıllık periyotlar halinde ve mevsimsel olarak incelediği DSS'lerinde, yaz, sonbahar ve k1ş mevsimlerinde ciddi bir değişikliğin olmadığını belirlemiştir. 10 yıllık periyotların ortalamasına göre yapılan analizlerde maksimum DSS'nin ilkbahar ve kış aylarında arttığını, yaz aylarında azaldığını, minimum DSS'nin ise ilkbaharda azaldığını yaz mevsiminde arttığını belirlemiştir. Ege Denizi için yapılmış olan [9]'da uydu verileri ile 1985-2008 arası için $0.045^{\circ} \mathrm{C} / \mathrm{y} 11,1992-2008$ arası için $0.055^{\circ} \mathrm{C} / \mathrm{y} 1 \mathrm{l}$ artış belirlemişlerdir. [10]'da 1985-2008 yılları arasında yaptıkları analiz ile tüm Akdeniz için $0.037{ }^{\circ} \mathrm{C} / \mathrm{y} 1$, Doğu Akdeniz için $0.042^{\circ} \mathrm{C} / \mathrm{y} 1 \mathrm{l}$ artış belirlemişlerdir. [11]'de tüm Akdeniz için 1982-2012 arasında $0.035^{\circ} \mathrm{C} / \mathrm{y} 1 \mathrm{l}$ artış belirlerken, ilkbahar-yaz-sonbahar-kış mevsimleri için sırasıyla 0.038-0.032-0.022-0.016 ${ }^{\circ} \mathrm{C} / \mathrm{y} 1 \mathrm{l}$ artış belirlemişlerdir. [12]'de 19822016 arası için $0.036{ }^{\circ} \mathrm{C} / \mathrm{y} 1 \mathrm{l}$ artış belirlemişlerdir.

$\mathrm{Bu}$ çalışmalarda elde edilen en büyük artışın tüm Akdeniz için 1992-2005 aralığında yapılmış olan [7]'de $0.06{ }^{\circ} \mathrm{C} / \mathrm{y}$ ıl olarak belirlendiği görülmektedir. Ayrıca [13] çalışma bölgesi olan Gökçeada’ya oldukça yakın mesafede olan Çanakkale'de uydu verilerini kullanarak; uzun dönem (35 yıl) deniz suyu sıcaklığı eğilimini araştırmış ve yıllık maksimum değerlerde $0.035^{\circ} \mathrm{C} / \mathrm{y} 11$, y1llık minimum değerde $0.020^{\circ} \mathrm{C} /$ y1l, yıllık ortalamada ise $0.028^{\circ} \mathrm{C} / \mathrm{y} 1 \mathrm{l}$ artış olduğunu belirlemişlerdir. Yaptıkları aylık analiz ile de en fazla artışı Kasım $\left(0.049^{\circ} \mathrm{C} / \mathrm{y} 11\right)$ ve Aralık $\left(0.043^{\circ} \mathrm{C} / \mathrm{y} 1\right)$ aylarında belirlemişlerdir. Görüldüğü gibi [6] haricindeki bütün araştırmacılar Akdeniz ve Ege Denizi için DSS'nın artış eğilimi gösterdiğini belirlemişlerdir.

Bu çalışmada Ege Denizi'nin kuzeyinde, Çanakkale Boğazı'nın kuzeybatısında yer alan Türkiye'nin en büyük adası olan Gökçeada'nın sıcaklık ve deniz suyu sıcaklıklarının zamansal değissimi ile aylık, yıllik ve mevsimsel eğilimi araştırılmıştır. DSS'nin değişimi literatürde yapılan çalışmaların çoğunluğunda bölgesel olarak ve çoğunlukla 
uydu verileri kullanılarak araştırılmıştır. Yerinde yapılan ölçümlerle elde edilmiş veriler ile yapılan analizler oldukça kısıtlıdır. Ayrıca çalışma alanları noktasal olarak ve daha ayrıntılı olarak göz önüne alındığında; tüm bölgede elde edilen sonuçlardan farklı sonuçlar da elde edilebilmektedir. Bu amaçla bu çalışmada Ege Denizi'nin kuzeyinde yer alan Gökçeada'nın noktasal olarak sicaklık ve deniz suyu sicaklıklarının aylık, yıllık ve mevsimlik olarak değişimi ve istatistiksel olarak anlamlılığı araştırılmıştır.

\section{2. Çalışma Alanı, Veriler ve Metot}

\section{1. Çalışma alanı}

Bu Çalışmada Ege Denizi'nin kuzeyinde, Gelibolu yarımadasının batısında, Çanakkale Boğazı'nın kuzeybatısında yer alan Türkiye'nin en büyük adası olan Gökçeada'nın sıcaklık ve DSS verilerinin homojenliği, zamansal değişimi ile aylık ve mevsimsel eğilimi araştırılmıştır. $40^{\circ} 11 \notin$ Kuzey ve $26^{\circ} 54 \varnothing$ Doğu koordinatlarındaki Gökçeada’nın konumu Şekil 1'de görülmektedir. 285 km² yüzölçümlü olan Gökçeada’nın 92 km kıyısı bulunmaktadır.

\subsection{Veriler}

Bu çalışmada Meteoroloji Genel Müdürlüğünün 17110 no.lu Gökçeada istasyonundan alınan sıcaklık ve deniz suyu sıcaklıkları ölçüm verileri kullanılmıştır. 2006-2015 zaman periyodu için aylık ortalama, aylık minimum ve aylık maksimum sicaklıklar ile aylık ortalama, ayl1k minimum ve aylık maksimum deniz suyu sicaklıkları verileri kullanılmıştır. Kullanılan verilerin istatistiksel özellikleri Tablo 2'de özetlenmiştir. Hem sıcaklık hem de deniz suyu sıcaklığı verilerinde belirlenen 10 yıllık zaman aralığı için eksik veri bulunmamaktadır. $\mathrm{Bu}$ istasyon için en düşük sicaklık $-8.9^{\circ} \mathrm{C}$, en yüksek sicaklık ise $40.8^{\circ} \mathrm{C}$ olarak ölçülmüştür. En düşük DSS $7.4^{\circ} \mathrm{C}$, en yükssek DSS $27.8^{\circ} \mathrm{C}$ olarak ölçülmüştür. 


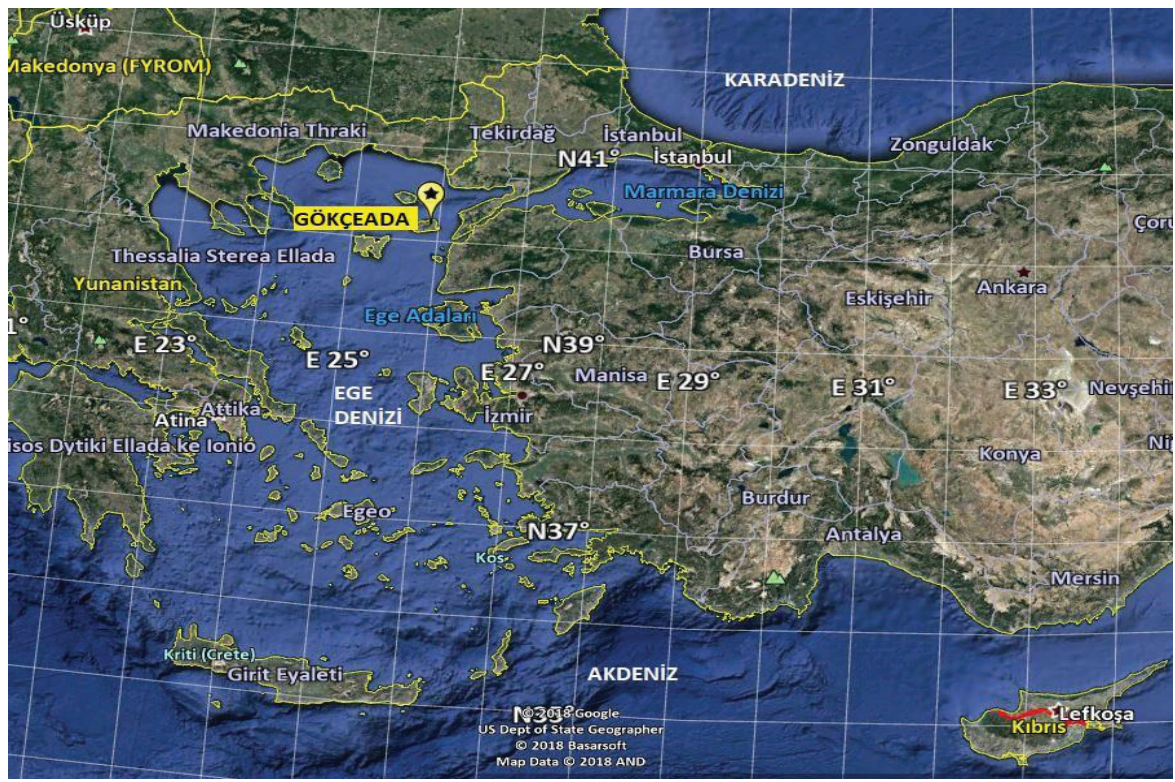

Şekil 1. Çalışma Alanı

Tablo 2. Sıcaklık ve Deniz Suyu Sıcaklıklarının(DSS) İstatistiksel Özellikleri

\begin{tabular}{ccccccc}
\hline & Ortalama & Minimum & Maksimum & Ortalama & Minimum & Maksi- \\
& Sicaklık & Sicaklık & Sicaklık & DSS & DSS & mum DSS \\
\hline Veri sayısı & 120 & 120 & 120 & 120 & 120 & 120 \\
Ortalama Değer & 16.1 & 7.4 & 26.2 & 16.5 & 15.0 & 18.4 \\
Minimum Değer & 3.6 & -8.9 & 14.0 & 7.5 & 7.4 & 7.5 \\
Maksimum Değer & 27.7 & 20.3 & 40.8 & 26.3 & 25.5 & 27.8 \\
Standart Sapma & 6.7 & 7.6 & 7.1 & 5.6 & 5.3 & 5.8 \\
Çarpıklık & 0.092 & -0.013 & 0.147 & 0.155 & 0.379 & -0.046 \\
\hline
\end{tabular}




\subsection{Metot}

Ölçüm verilerinin homojenliğinin belirlenmesi için literatürde hidrolojik ve meteorolojik verilerin homojenliğinin belirlenmesinde en çok yararlanılan 4 test kullanılmıştır: Standart Normal Homejenlik testi (SNHT) [14], Buishand Aralık Testi [15], Pettitt test [16] ve Von Neumann Oran Testi [17]. SNHT, Buishand ve Pettit testleri zaman serisinde kırılma noktasının yerini belirleyebilmektedir.

Eğilim analizi için parametrik ve parametrik olmayan istatistiksel metotlar kullanılmaktadır. Parametrik olmayan metotlar; eksik verilerin olduğu zaman serileri ile de kullanılabilmesi ve herhangi bir dağılıma uygun olma zorunluluğu olmaması nedeniyle daha çok tercih edilmektedir. Özellikle hidrolojik ve meteorolojik çalışmalarda zaman serilerinin incelenmesinde parametrik olmayan metotlardan biri olan Theil-Sen metodu ([18], [19]) kullanılmaktadır. Theil-Sen Metodu en küçük kareler yöntemine alternatif olarak kullanılmaktadır. Bu metot ilk olarak basit lineer modeller için uygulanmış, daha sonra çoklu lineer modeller için geliştirilmiştir. Bu çalışmada ayrıca en küçük kareler yöntemi ile de eğilim analizi yapılmış ve iki metodun sonuçları karşılaştırılmıştır. Bir diğer parametrik olmayan Mann-Kendall Testi ([20],[21]) ile de anlamlılık düzeyi belirlenmiştir.

\section{Bulgular ve Tartışma}

4 farklı homojenlik testi ile 2006-2015 zaman aralığındaki 10 yıllık ortalama sicaklık, minimum sicaklık, maksimum sicaklık, ortalama DSS, minimum DSS ve maksimum DSS parametrelerinin aylık, mevsimlik ve yıllık ortalama, yıllık minimum, ve yıllık maksimum verilerine göre homojenlik analizi gerçekleştirilmiştir. [22] ve [23]'te 1 veya sifir testin homojen olmadığ 1 hipotezini reddetmesi halinde veri setini 'kullanışlı' olarak tabir etmiştir. Testlerden en az üçü \%5 anlamlılık düzeyinde homojenlik hipotezini kabul 
ettiğinde, veri seti homojen olarak kabul edilmiştir. Bu kabule göre bütün 10 yıllık veri setlerinin aylık, mevsimlik, yıllık ortalama, yıllık minimum ve yıllık maksimum verilerinin homojen olduğu belirlenmiştir. Sadece ortalama sıcaklık verilerinin Eylül ayı için bütün test yöntemleri ile homojen olmadığı ve 2009 yılında bir kırılma olduğu belirlenmiştir.

Gökçeada istasyonun sıcaklık ve DSS'nin zamansal değişimi Şekil 2'de verilmiştir. Aylık ortalama sıcaklık, aylık minimum s1caklık, aylık maksimum sicaklık, aylık ortalama DSS, aylık minimum DSS, aylık maksimum DSS verileri kullanılarak elde edilmiş grafiklerde aylık ortalama ve yıllık ortalama değerleri görülmektedir. En küçük kareler yöntemi ile elde edilen eğilim değerleri Tablo 3'te özetlenmiştir.

Tablo 3. Sıcaklık ve Deniz Suyu Sıcaklıklarının Eğilim Değerleri

\begin{tabular}{ccccccc}
\hline & \multicolumn{2}{c}{ ORTALAMA } & \multicolumn{2}{c}{ MINIMUM } & \multicolumn{2}{c}{ MAKSIMUM } \\
& Aylık & Y1llk & Aylık & Y1ll1k & Aylı & Y1llk \\
\hline S1caklık & 0.1506 & 0.0784 & 0.2077 & 0.1271 & 0.1184 & 0.0569 \\
DSS & 0.178 & 0.075 & 0.0587 & -0.0327 & 0.1213 & 0.0153 \\
\hline
\end{tabular}

Aylık ortalama verileri ile sıcaklığın $0.1506^{\circ} \mathrm{C} / \mathrm{y} 1$, DSS'nin ise $0.178^{\circ} \mathrm{C} / \mathrm{y} 1 \mathrm{l}$ artış gösterdiği; yıllık ortalama verileri ile sıcaklığın $0.0784^{\circ} \mathrm{C} / \mathrm{y} 11, \mathrm{DSS}$ 'nin ise $0.075^{\circ} \mathrm{C} / \mathrm{y} 1 \mathrm{l}$ artış gösterdiği belirlenmiştir. Böylece aylık analizde elde edilen eğilimlerin yıllık ile hesaplanan eğilimin yaklaşık iki katı hesaplandığı görülmüştür. Aylık minimum verileri ile sicaklığın $0.2077^{\circ} \mathrm{C} / \mathrm{y} 1 \mathrm{l}, \mathrm{DSS}$ 'nin ise $0.0587^{\circ} \mathrm{C} /$ yıl artış gösterdiği; yıllık ortalama verileri ile sıcaklığın $0.1271^{\circ} \mathrm{C} /$ yıl artış, DSS'nin ise $0.0327^{\circ} \mathrm{C} / \mathrm{y} 1 \mathrm{l}$ azalan eğilim gösterdiği belirlenmiştir. Yani DSS, aylık ortalamaya göre hesaplandığında artan eğilim, yıllığa göre hesaplandığında azalan eğilim göstermektedir. Aylık maksimum verileri ile sicaklığın $0.1184^{\circ} \mathrm{C} / \mathrm{y} 11$, DSS'nin ise $0.1213^{\circ} \mathrm{C} / \mathrm{y} ı 1$ artış gösterdiği; yıllık ortalama verileri ile sıcaklığın 
$0.0569^{\circ} \mathrm{C} / \mathrm{y} 1 \mathrm{l}, \mathrm{DSS}$ 'nin ise $0.0153^{\circ} \mathrm{C} / \mathrm{yll}$ artan eğilim gösterdiği belirlenmiştir. Yıllık ortalama analizlerde, aylık oluşan ekstrem durumların etkisinin azaldığı görülmektedir. Ekstrem durumların analizi için; sıcaklık ve DSS'nin yıllık ortalama, y1llık minimum ve yıllık maksimum değerleri ile eğilimlerine bakıldığında bütün maksimum değerlerin azalan eğilim, bütün minimum değerlerinde artan eğilim gösterdiği belirlenmiş̧ir.

Şekil 3'te Gökçeada'nın aylık ortalama, aylık minimum ve aylık maksimum DSS mevsimsel olarak incelenmiştir. En küçük kareler yöntemine göre elde edilen eğilim değerleri ise Tablo 4 'te verilmiştir. Bütün veri setleri için yaz mevsiminde azalan eğilim belirlenirken kış mevsimi için artan eğilim belirlenmiştir. Aylık Ortalama DSS, yaz mevsimi hariç diğer mevsimlerde artış eğilimi göstermiştir. Aylık minimum DSS sadece kış mevsiminde artış eğilimi, diğer mevsimlerde azalma eğilimi göstermiştir. Aylık maksimum DSS ise ilkbahar ve yaz mevsimlerinde azalan eğilim, sonbahar ve kış mevsimlerinde artı̧̧ eğilimi göstermiştir. 


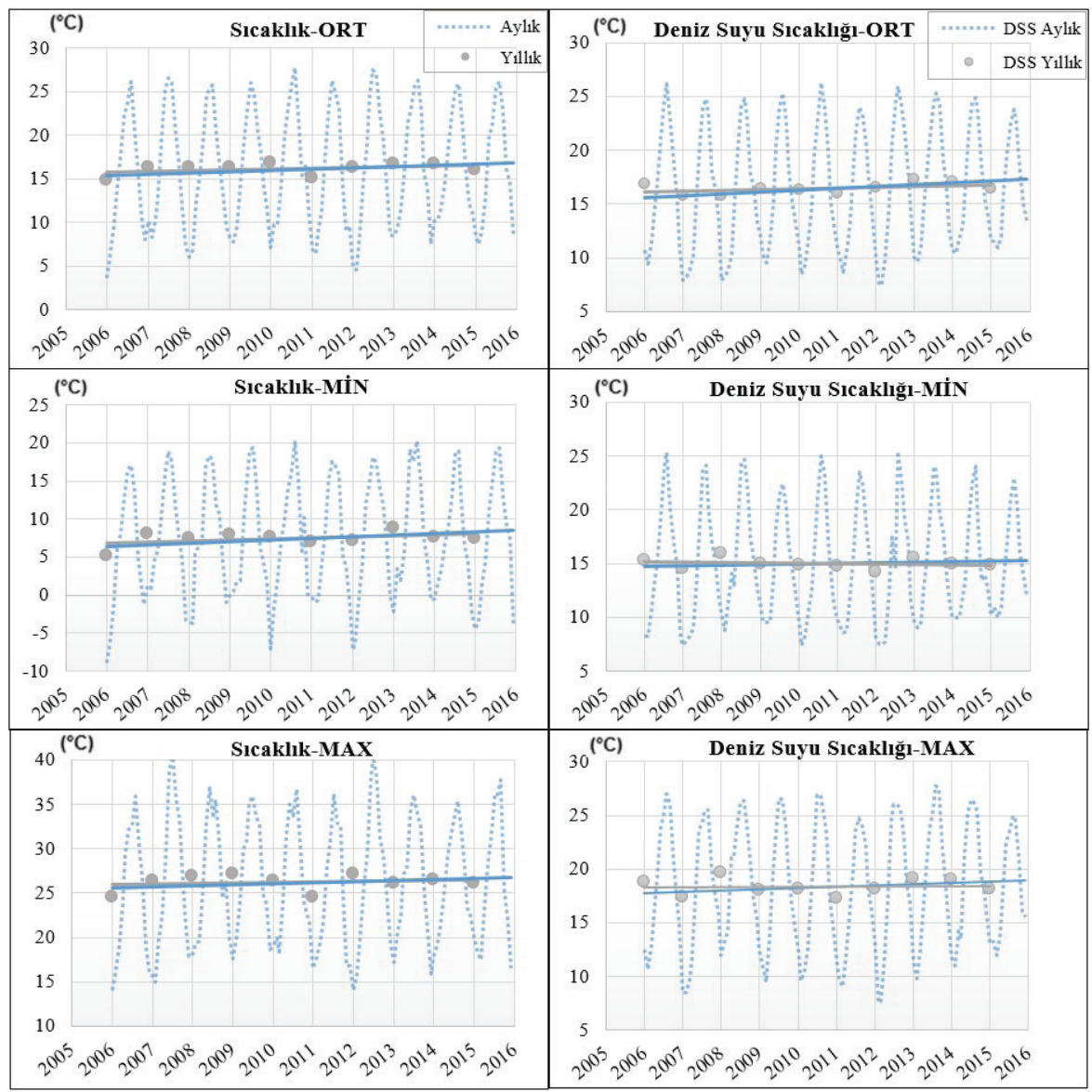

Şekil 2. Gökçeada'da Ortalama, Minimum, Maksimum Sicaklık ve Deniz Suyu Sıcaklıklarının Zamanla Değişimi

Ayrıca Tablo 4'te Gökçeada'ya en yakın istasyonlardan biri olan Çanakkale istasyonu için uydu verileri kullanılarak yapılmış olan çalışmadan [13]'te elde edilmiş mevsimsel eğilim değerleri de verilmiştir. $\mathrm{Bu}$ çalışmadan elde edilen eğilim değerleri aylık ortalama DSS verilerinden elde edilmiştir. Gökçeada DSS de, Çanakkale istasyonuna benzer olarak sonbahar, kış ve ilkbahar mevsimlerinde artış eğilimi göstermiştir. Ancak Gökçeada' da Çanakkale istasyonuna göre kış $\left(0.1925^{\circ} \mathrm{C} / \mathrm{y} 1 \mathrm{l}\right)$ ve ilkbahar $\left(0.1178^{\circ} \mathrm{C} / \mathrm{y} 1 \mathrm{l}\right)$ mevsimlerinde çok daha 
büyük artış eğilimi hesaplanmıştır. Arada oluşan farkın sebebinin bu çalışmada kullanılan verilerin ölçüm verisi olmasından, ölçüm tekniği-zamanı vb. parametrelerin etkisi olduğu düşünülmektedir. Ayrıca kullanılan zaman serisinin diğer çalışmaya göre daha kısa olmasından kaynaklanabileceği düşünülmektedir.
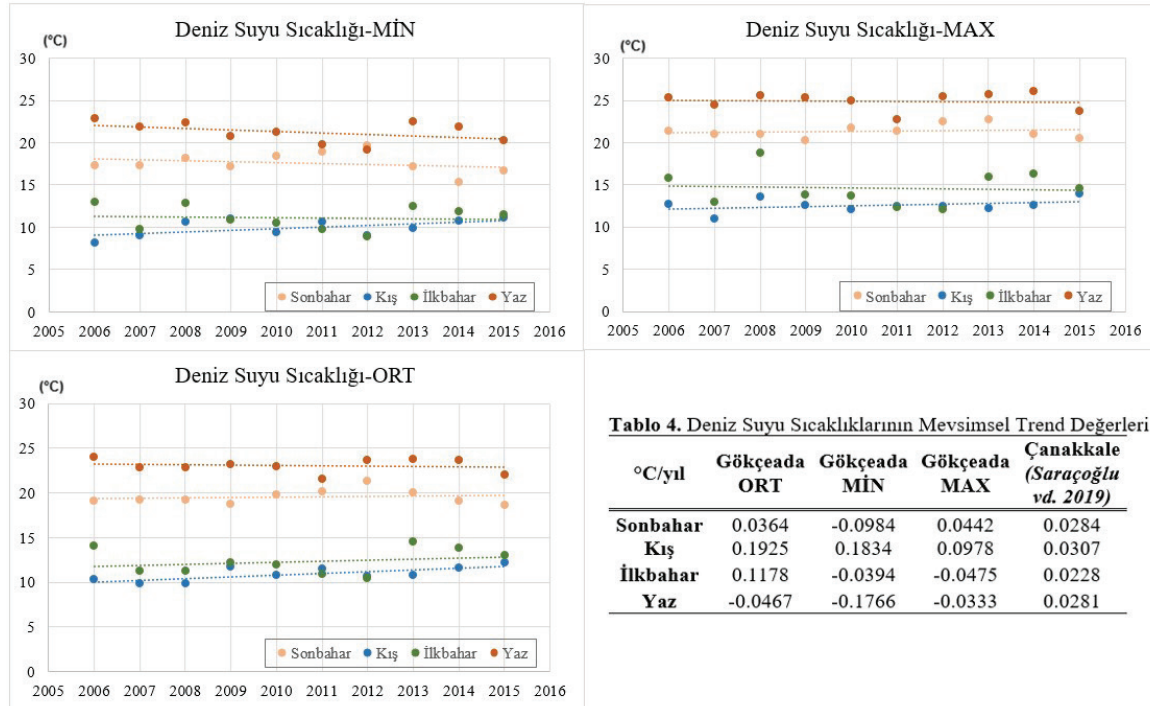

Tablo 4. Deniz Suyu Sıcaklıklarının Mevsimsel Trend Değerleri

\begin{tabular}{ccccc}
\hline${ }^{\circ}$ C/yıl & $\begin{array}{c}\text { Gökçeada } \\
\text { ORT }\end{array}$ & $\begin{array}{c}\text { Gökçeada } \\
\text { MiN }\end{array}$ & $\begin{array}{c}\text { Gökçeada } \\
\text { MAX }\end{array}$ & $\begin{array}{c}\text { Çanakkale } \\
\text { (Saraçoğlu } \\
\text { vd. 2019) }\end{array}$ \\
\hline \hline $\begin{array}{c}\text { Sonbahar } \\
\text { Kıș }\end{array}$ & 0.0364 & -0.0984 & 0.0442 & 0.0284 \\
İlkbahar & 0.1925 & 0.1834 & 0.0978 & 0.0307 \\
Yaz & -0.0467 & -0.0394 & -0.0475 & 0.0228 \\
\hline
\end{tabular}

Şekil 3. Gökçeada Aylık Minimum, Maksimum ve Ortalama Deniz Suyu Sıcaklıklarının Mevsimsel olarak Zamanla Değişimi

Gökçeada aylık ortalama, aylık minimum ve aylık maksimum s1caklık değerlerinin 2005-2016 zaman aralığı için Theil-Sen metoduyla elde edilmiş $p$ ve eğilim değerleri Tablo 5 'te verilmiştir. Bu zaman aralığ için çoğunlukla ayların istatiksel olarak belirgin olmadığ görülmüştür. Aylık ortalama sıcaklık değerlerinin sadece Eylül ayı için \%10 anlamlılık düzeyinde $0.256{ }^{\circ} \mathrm{C} / \mathrm{y} 11$ arttığ görülmektedir. Aylık minimum sıcaklık değerinin Ağustos ayı için \%20 anlamlılık düzeyinde $0.238^{\circ} \mathrm{C} / \mathrm{y} 1$, aylık maksimum sicaklık değerinde ise $\% 20$ anlamlılık düzeyinde Ocak ayında $0.417^{\circ} \mathrm{C} / \mathrm{y} 1 \mathrm{l}$ artan, Mayıs ve Haziran aylarında sırasıyla $0.3^{\circ} \mathrm{C} / \mathrm{y} 11$ ve $0.583^{\circ} \mathrm{C} / \mathrm{y} 1 \mathrm{l}$ azalan eğilim belirlenmiştir. 
Mevsimlere göre aylık ortalama, aylık minimum ve aylık maksimum DSS'nin her iki yöntemle elde edilmiş olan eğilim değerleri Tablo 6'da verilmiştir. Mann Kendall ile elde edilen anlamlılık düzeyleri de aynı tabloda yer almaktadır. \%5 anlamlılık düzeyi için bütün verilerin istatistiksel olarak belirgin olmadığı görülmüştür. Sadece aylık minimum DSS için; yaz mevsiminde \%20 anlamlılık düzeyinde En küçük kareler yöntemi ile $0.18^{\circ} \mathrm{C} / \mathrm{y} 1$, Theil Sen ile $0.283^{\circ} \mathrm{C} / \mathrm{y} 1 \mathrm{l}$ azalan eğilim; kış mevsiminde ise \%10 anlamlılık düzeylerinde en küçük kareler yöntemi ile $0.18^{\circ} \mathrm{C} / \mathrm{y} 1$, Theil Sen ile $0.248^{\circ} \mathrm{C} / \mathrm{y} 1 \mathrm{l}$ artan eğilim belirlenmiştir. Görüldüğü gibi özellikle kış ve ilkbahar mevsimlerinde literatürdeki tüm Akdeniz ve Ege denizi için yapılan çalışmalardan oldukça fazla artan eğilim değerleri elde edilmiştir. Noktasal olarak ölçülen ve değişimi incelenen sıcaklık ve deniz suyu sıcaklıklarının tüm bölge için elde edilen sonuçlardan farklı olabileceği görülmüştür. Ayrıca istatistiksel olarak belirgin olan Mayıs ve Haziran aylarındaki azalma oldukça dikkat çekicidir. Kısa dönem analizlerinde ekstrem durumlardan çok etkilendiğinden daha uzun dönem analizlerine ihtiyaç vardır. Ayrıca iki farklı yöntemle elde edilmiş eğilim değerlerinin birbirinden oldukça farklı olduğu görülmüştür. [13]'te iki metot sonuçlarının birbirine oldukça yakın olduğu göz önüne alınırsa; bu çalışmada farklı olmasının en belirgin sebebinin, zaman serisinin kısal1ğından kaynaklandığı düşünülmektedir. 
Tablo 5. Gökçeada Aylık Sıcaklıklarının Eğilim Değerleri (Theil Sen)

\begin{tabular}{ccccccc} 
& \multicolumn{2}{c}{ Ortalama } & \multicolumn{2}{c}{ Minimum } & \multicolumn{2}{c}{ Maksimum } \\
& $\mathrm{p}$ & ${ }^{\circ} \mathrm{C} / \mathrm{y} 1 \mathrm{l}$ & $\mathrm{p}$ & ${ }^{\circ} \mathrm{C} / \mathrm{y} 11$ & $\mathrm{p}$ & ${ }^{\circ} \mathrm{C} / \mathrm{y} 11$ \\
Ocak & 0.367 & 0.329 & 0.858 & -0.050 & 0.152 & $\mathbf{0 . 4 1 7}$ \\
Şubat & 0.530 & 0.150 & 0.474 & 0.267 & 0.474 & 0.200 \\
Mart & 0.788 & -0.056 & 1.000 & 0.033 & 0.858 & 0.120 \\
Nisan & 0.721 & 0.075 & 1.000 & -0.083 & 1.000 & 0.113 \\
Mayıs & 0.592 & 0.100 & 0.210 & 0.340 & 0.178 & $\mathbf{- 0 . 3 0 0}$ \\
Haziran & 0.243 & -0.200 & 1.000 & -0.050 & 0.152 & $\mathbf{- 0 . 5 8 3}$ \\
Temmuz & 1.000 & 0.000 & 0.721 & 0.100 & 0.530 & 0.125 \\
Ağustos & 1.000 & 0.013 & 0.178 & $\mathbf{0 . 2 3 8}$ & 1.000 & 0.000 \\
Eylül & 0.074 & $\mathbf{0 . 2 5 6}$ & 0.419 & 0.163 & 0.419 & 0.250 \\
Ekim & 1.000 & -0.043 & 0.474 & 0.213 & 0.653 & 0.100 \\
Kasım & 0.243 & 0.225 & 0.318 & 0.400 & 1.000 & 0.025 \\
Aralık & 0.858 & 0.050 & 0.653 & -0.150 & 0.858 & 0.160 \\
\hline
\end{tabular}

Tablo 6. Mevsimsel Deniz Suyu Sıcaklıklarının Eğilim Değerleri Karşılaştırması ve Belirginlikleri

\begin{tabular}{|c|ccc|ccc|ccc|}
\hline & \multicolumn{3}{|c|}{ Ortalama } & \multicolumn{3}{c|}{ Minimum } & \multicolumn{3}{c|}{ Maksimum } \\
\cline { 2 - 10 } DSS & $\begin{array}{c}\text { En küçük } \\
\text { kareler } \\
\left({ }^{\circ} \mathrm{C} / \mathrm{y} 1\right)\end{array}$ & $\mathrm{p}$ & $\begin{array}{c}\text { Sen's } \\
\left({ }^{\circ} \mathrm{C} / \mathrm{y} 1\right)\end{array}$ & $\begin{array}{l}\text { En küçük } \\
\text { kareler } \\
\left({ }^{\circ} \mathrm{C} / \mathrm{y} 11\right)\end{array}$ & $\mathrm{p}$ & $\begin{array}{c}\text { Sen's } \\
\left({ }^{\circ} \mathrm{C} / \mathrm{yl} 1\right)\end{array}$ & $\begin{array}{c}\text { En küçük } \\
\text { kareler } \\
\left({ }^{\circ} \mathrm{C} / \mathrm{y} 1 \mathrm{l}\right)\end{array}$ & $\mathrm{p}$ & $\begin{array}{c}\text { Sen's } \\
\left({ }^{\circ} \mathrm{C} / \mathrm{y} 1 \mathrm{l}\right)\end{array}$ \\
\hline Sonbahar & 0.0364 & 0.858 & 0.067 & -0.0984 & 0.721 & -0.044 & 0.0442 & 0.858 & 0.017 \\
K1ş & 0.1925 & 0.210 & 0.133 & 0.1834 & 0.074 & 0.248 & 0.0978 & 0.721 & 0.033 \\
Illkbahar & 0.1178 & 0.721 & -0.119 & -0.0394 & 0.592 & -0.138 & -0.0475 & 1.000 & -0.133 \\
Yaz & -0.0467 & 0.474 & -0.050 & -0.1766 & 0.178 & -0.283 & -0.0333 & 0.721 & 0.048 \\
\hline
\end{tabular}




\section{Sonuçlar}

Gökçeada aylık ortalama sıcaklık, aylık minimum sıcaklık, aylık maksimum sıcaklık ve aylık ortalama deniz suyu sıcaklığı, aylık minimum deniz suyu sıcaklığı, aylık maksimum deniz suyu sıcaklıkları kullanılarak 2005-2016 yılları arasındaki 10 yıllık zaman aralığı için aylık, mevsimlik ve yıllık eğilim analizi yapılmıştır. Bu çalışmadan elde edilen sonuçlar aşağıda özetlenmiştir.

- Bütün 10 yıllık veri setlerinin aylık, mevsimlik, y1llık ortalama, yıllık minimum ve yıllık maksimum serilerinin 4 farklı metot ile homojen olduğu belirlenmiştir. Sadece ortalama sıcaklık verilerinin Eylül ayı için bütün test yöntemleri ile homojen olmadığı ve 2009 yılında bir kırılma olduğu belirlenmiştir.

- Hem sicaklık hem de DSS için aylık ortalama verilerinin; ayl1k analizde elde edilen eğilimlerin yıllık ile hesaplanan eğilimin yaklaşık iki katı olduğu belirlenmiştir.

- Aylık minimum DSS verileri ile aylık ortalamaya göre hesaplandığında artan eğilim, yıllığa göre hesaplandığında azalan eğilim belirlenmiştir.

- Yıllık ortalama analizlerde, aylık oluşan ekstrem durumların etkisinin azaldığı görülmüştür. Ekstrem durumların analizi için; s1caklık ve DSS'nın yıllık ortalama, yıllık minimum ve yıllık maksimum değerleri ile eğilimlerine bakıldığında bütün maksimum değerlerin azalan eğilim, bütün minimum değerlerinde artan eğilim gösterdiği belirlenmiştir.

- Aylık ortalama DSS, en küçük kareler yöntemi ve Theil Sen metodu ile elde edilen sonuçlara göre yaz mevsiminde azalan eğilim belirlenirken kış mevsimi için artan eğilim belirlenmiştir.

- Aylık minimum DSS'nın her iki yöntem ile sadece kış mevsiminde artış eğilimi, diğer mevsimlerde azalma eğilimi göstermiştir.

- Aylık maksimum DSS ise her iki yöntem ile çoğunlukla ilkbahar ve yaz mevsimlerinde azalan eğilim, sonbahar ve kış 
mevsimlerinde artış eğilimi göstermiştir. Böylece bütün aylık verilere göre (aylık minimum- aylık ortalama- aylık maksimum) yaz mevsiminde azalma, kış mevsiminde artış eğilimi olduğu belirlenmiştir.

- Gökçeada DSS da, Çanakkale istasyonuna [13] benzer olarak sonbahar, kış ve ilkbahar mevsimlerinde artış eğilimi göstermiştir. Ancak Gökçeada' da Çanakkale istasyonuna göre kış $\left(0.1925^{\circ} \mathrm{C} / \mathrm{y} 1 \mathrm{l}\right)$ ve ilkbahar $\left(0.1178^{\circ} \mathrm{C} / \mathrm{y}\right.$ ll $)$ mevsimlerinde çok daha büyük artış eğilimi hesaplanmıştır. Bu farkın ölçüm verilerinden ve kısa süreli zaman serisi olmasından kaynaklandığı düşünülmektedir.

- Aylık ortalama sicaklık değerlerinin Theil Sen Metoduyla elde edilen sonuçlara göre sadece Eylül ayı için \%10 anlamlılık düzeyinde $0.256{ }^{\circ} \mathrm{C} / \mathrm{y} 1 \mathrm{l}$ arttı̆ğ görülmektedir. Aylık minimum s1caklık değerinin Ağustos ayı için \%20 anlamlılık düzeyinde $0.238^{\circ} \mathrm{C} / \mathrm{y} 1$, aylık maksimum sicaklık değerinde ise $\% 20$ anlamlilık düzeyinde Ocak ayında $0.417^{\circ} \mathrm{C} / \mathrm{y} 1 \mathrm{l}$ artan, Mayıs ve Haziranda sirasıyla $0.3^{\circ} \mathrm{C} / \mathrm{y} 11$ ve $0.583^{\circ} \mathrm{C} / \mathrm{y} 1 \mathrm{l}$ azalan eğilim belirlenmiştir. Görüldüğü gibi hesaplanan artış eğilimlerinin; literatürde tüm Akdeniz veya Ege denizi için hesaplanan artış eğilimlerinden oldukça yüksek olduğu belirlenmiştir.

\section{Teșekkür}

Gökçeada ölçüm verileri için Meteoroloji Genel Müdürlüğüne teşekkür ederiz. 


\section{Kaynaklar}

[1] IPCC, Climate Change 2013: The Physical Science Basis. The contribution of Working Group I to the Fifth Assessment Report of the Intergovernmental Panel on Climate Change. In: Stocker, T.F., Qin, D., Plattner, G.-K., Tignor, M., Allen, S.K., Boschung, J., Nauels, A., Xia, Y., Bex, V., Midgley, P.M. (Eds.), Cambridge University Press, Cambridge, United Kingdom and New York, NY, USA (1535 pp.) (2013).

[2] Rayner, N. A., Parker D.E., Horton E.B., Folland C.K., Alexander L.V., Rowell D.P., Kent E.C. Kaplan A, Global analyses of sea surface temperature, sea ice, and night marine air temperature since the late nineteenth century, Journal of Geophysical Research Atmospheres, 108, D14. (2003)

[3] Ishii, M., Shouji, A., Sugimoto S., ve Matsumoto T., Objective analyses of sea surface temperature and marine meteorological variables for the 20th century using icoads and the Kobe collection. Int. Journal of Climatology, 25, (2005) 865-879.

[4] Smith, T. M., Reynolds R. W., Peterson T. C., ve Lawrimore J., "Improvements to NOAA's historical merged land-ocean surface temperature analysis (18802006)", J. Clim.,21: (2008), 2283-2296.

[5] Kennedy, J. J., Rayner N. A., Smith R. O., Parker D. E, ve Saunby M., Reassessing biases and other uncertainties in sea surface temperature observations measured in situ since 1850: 2. Biases and homogenization, J. Geophys. Res Atmos., 116, D14104 (2011).

[6] D'Ortenzio F., Marullo S., Santoleri R., Validation of AVHRR Pathfinder SST over the Mediterranean Sea, Geophys. Res. Lett., 27 (2): (2000), 241-244.

[7] Criado-Aldeanueva F., Del Rio J., Garcia-Lafuente J., Steric and mass-induced Mediterranean Sea level trends from 14 years of altimetry data, Global Planet Chang 60 (3-4): (2008) 563-575.

[8] Kaskatı M.T., Kuzey Ege'nin Oşinografik Parametrelerinin Mevsimsel ve Yıllar Bazında İncelenmesi, Yüksek Lisans Tezi, İstanbul Teknik Üniversitesi, Fen Bilimleri Enstitüsü, (2010).

[9] Skliris N., Sofianos S., Gkanasos A., Axaopoulos P., Mantziafou A., Vervatis V., Long-term Sea surface temperature variability in the Aegean Sea, Advances in Oceanography and Limnology, 2(2): (2011) 125-139.

[10] Skliris N., Sofianos S., Gkanasos A., Mantziafou A., Vervatis V., Axaopoulos P., Lascaratos A., Decadal-scale variability of sea surface temperature in the Mediterranean Sea in relation to atmospheric variability, Ocean Dynam., 62 (1), (2012). 13-30. 
[11] Shaltout M., ve Omstedt A., Recent sea surface temperature trends and future scenarios for the Mediterranean Sea, Oceanologia, 56 (3): (2014) 411-443.

[12] Pastor F., Valiente J.A. ve Palau J.L., Sea Surface Temperature in the Mediterranean: Trends and Spatial Patterns (1982-2016), Pure Appl. Geophys. 175 (2018), 4017-4029.

[13] Saraçoğlu F.A, Ayat B., Saraçoğlu K.E., Aydoğan B., Çanakkale Deniz Suyu Sıcaklığının Uydu Verileri ile Uzun Dönem Analizi (1982-2016), 10.Hidroloji Kongresi, (2019, Ekim), Muğla, Muğla Sıtkı Koçman Üniversitesi.

[14] Alexandersson H., A homogeneity test applied to precipitation data., Journal of Climatology, 6: (1986) 661-675.

[15] Buishand TA. Some methods for testing the homogeneity of rainfall records. Journal of Hydrology 58: (1982) 11- 27.

[16] Pettitt A.N., A non-parametric approach to the change-point detection, Applied Statistics 28: (1979) 126-135.

[17] Von Neumann J., Distribution of the ratio of the mean square successive difference to the variance., Annals of Mathematical Statistics 13: (1941) 367-395.

[18] Theil, H., A rank-invariant method of linear and polynomial regression analysis, I. Proc. Kon. Ned. Akad. v. Wetensch. A53: (1950), 386-392.

[19] Sen, P.K., Estimates of the regression coefficient based on Kendall's tau, J. Amer. Statist. Assoc. 63: (1968) 1379-1389.

[20] Mann, H.B., Nonparametric tests against trend, Econometrica. 13: (1945) 245259.

[21] Kendall, M.G., Rank Correlation Methods, Second ed., Hafner, New York. (1970).

[22] Schönwiese CD, Rapp J., Climate Trend Atlas of Europe Based on Observations 1891-1990. Kluwer: Dordrecht, The Netherlands. (1997).

[23] Wijngaard J.B., Klein Tank A.M.G., Können G.P., Homogeneity og 20th Cwntury European Daily Temperature and Precipitation Series, International journal of Climatology, 23: (2003) 679-692. Doi: 10.1002/joc.906 
